\title{
Seyahat Motivasyonlarının X, Y ve Z Kuşaklarına Göre Farklılıklarının İncelenmesi Üzerine Bir Araştırma
}

DOI: $10.26466 /$ opus.693787

\author{
Serdar Çöp* - Salim İbiş̧* - Özgür Kızıldemir*** \\ *Dr. Öğr. Üyesi, İstanbul Gelişim Üni., İktisadi İdari ve Sosyal Bilimler Fak.,İstanbul/Türkiye \\ E-Posta: scop@gelisim.edu.tr \\ ORCID: $\underline{0000-0002-1101-5676}$ \\ **Dr. Öğr. Üyesi, İstanbul Galata Üni., Sanat ve Sosyal Bilimler Fak., İstanbul/Türkiye \\ E-Posta: salim.ibis@galata.edu.tr \\ ORCID: 0000-0002-2404-9218 \\ ***Dr. Öğr. Üyesi, İstanbul Gelişim Üni., Uygulamalı Bilimler Yüksekokulu, İstanbul/Türkiye \\ E-Posta: okizildemir@gelisim.edu.tr \\ ORCID: 0000-0003-4040-4547
}

\section{Öz}

Turizm pazarlamasında yaş faktörü önemli bir pazar bölümlendirme kriteri olarak kabul edilmektedir. Bireyler doğdukları yıla göre X, Y ve Z şeklinde belli kuşaklara ayrılmaktadır. Her kuşă̆ın kendine has öne çıkan bazı davranış özellikleri bulunmaktadır. Bu davranış özellikleri turistik ürün ve hizmet tercihinde de belirleyici rol oynayabilmektedir. Her yaş grubunun farklılı gösteren seyahat davranışlarının belirlenmesi ve buna uygun ürün ve hizmet geliştirilmesi turizm pazarlaması açısından önemli bir konudur. Öte yandan insanları seyahate yönelten farklı nedenler bulunmaktadır. Seyahat motivasyonu olarak açıklanan bu nedenler bireyleri hem seyahate iten "itici faktörler", hem de gidecekleri yerde onları çeken "çekici faktörler" olarak açıklanmaktadır. Bu araştırmanın amacı; X, Y ve Z kuşaklarının seyahat motivasyonlarının farklılık gösterip göstermediğini incelemektir. Bu amaç doğrultusunda her kuşaktan katılımclların dâhil edildiği 566 kişiye kolayda örnekleme tekniği ile ulaşılarak seyahat motivasyonlarına ilişkin hazırlanan anket formu doldurtulmuştur. Elde edilen veriler nicel analiz teknikleri ile analiz edilmiştir. Yapılan analizler sonucunda yedi boyuttan oluşan seyahat motivasyonlarının kuşaklara göre bazı farklllıklar gösterdiği görülmüş̧ür.

Anahtar Kelimeler: Turizm, seyahat motivasyonu, X, Y,Z kuşağı. 


\title{
A Study on Investigation of Differences of Travel Motivations According to $\mathrm{X}, \mathrm{Y}$ and $\mathrm{Z}$ Generations
}

\begin{abstract}
In tourism marketing, age factor is accepted as an important market segmentation criterion. Individuals are divided into certain generations in the form of $X, Y$ and $Z$ according to the year they were born. Each generation has some distinctive behavioral features. These behavioral characteristics can also play a decisive role in the choice of tourist products and services. Determining the different travel behaviors of each age group and developing suitable products and services is an important issue in terms of tourism marketing. On the other hand, there are different reasons leading people to travel. These reasons, which are explained as travel motivation, are explained as both "driving factors" that push individuals to travel and "attractive factors" that attract them at their destination. The purpose of this research, to examine whether travel motivations of $X, Y$ and $Z$ generations differ. For this purpose, 566 people, including participants from each generation, were easily reached by sampling technique and a questionnaire prepared for travel motivations was filled. The data obtained were analyzed by quantitative analysis techniques. As a result of the analyzes, it was seen that the travel motivations consisting of seven dimensions differed according to the generations.
\end{abstract}

Keywords: Tourism, travel motivation, $X, Y, Z$ generation 


\section{Giriş}

Toplumda sosyal, ekonomik ve teknolojik anlamdaki değişimler insanların değer yargıları, tutumları, davranış biçimleri, yaşam şekilleri gibi pek çok konu üzerinde etkili olmaktadır. Artan rekabet koşulları tüketici davranışların derinlemesine incelemeyi gerekli kılmakta tüketicilerin tercihleri üzerine özel araştırmalar yapılmasını zorunlu hale getirmektedir (Kotler ve Armstrong, 2004). Küreselleşme, toplumsal değişim, yaygın teknoloji kullanımı gibi faktörler insanların yaşam tarzı, istek ve beklentileri üzerinde önemli etkiler oluşturmaktadır. Turizm tercihleri de bu faktörlerden etkilenmektedir.

Bireylerin sosyo-ekonomik durumları, yaşları, yaşam biçimlerine göre satın alma davranışları da farklılık göstermektedir. Bu durum hedef kitlelere yönelik farklı pazarlama yöntemlerine gidilmesini gerektirmektedir. Farklı kuşakların yaşam biçimlerini bilmek, tüketim alışkanlıklarını anlamak ve seyahat tercihleri konusunda fikir sahibi olmak pazarlama faaliyetlerinin doğru ve etkin yürütülmesi açısından son derece önemlidir. Kuşak farklılıklarının farkına varılması, karar verme tarzlarının belirlenmesi ve bu farklılıklara uygun ürün ve hizmet pazarlamasının yapılması işletmeler için de önem taşıyan bir konudur.

Turizm endüstrisinde turistlere yönelik pazar bölümlerinin oluşturulmasında kullanılan yöntemlerden biri de kuşaklara göre pazar bölümlendirme yöntemidir. Her kuşağın kendine has farklı istek, arzu ve beklentileri olduğu, bunun da satın alma davranışlarını etkilediği düşünüldüğünde bu tür bölümlendirmeler pazarlama alanına pek çok avantaj sağlamaktadır (Serçek ve Serçek, 2017).

$X, Y$ ve $Z$ kuşakları günümüz turist profili olarak ele alındığında genel özelliklerinin bilinmesi, seyahat, konaklama, yeme içme, eğlenme tercihlerinin anlaşılması ve buna uygun ürün ve hizmet oluşturulması gerekmektedir. Bu çalışmada kuşakların seyahat motivasyonlarının belirlenmesi ve seyahat motivasyonlarının kuşaklara göre farklılıklarının incelenmesi amaçlanmıştır. Elde edilen veriler ile yapılan analizler sonucunda ortaya çıkan bulgular açıklanmıştır. Çalışma sonuçlarının gerek turizm literatürüne gerekse turizm pazarlamacılarına katkı sağlayacağı düşünülmektedir. 


\section{Kuşak Kavramı ve Kuşaklar}

Türk Dil Kurumu Toplum Bilimi Sözlüğü kuşak kelimesini “yaklaşık yirmi beş otuz yıllık yaş kümelerini oluşturan bireyler öbeği, göbek, nesil, batın, jenerasyon" olarak tanımlamaktadır. Türk Dil Kurumu Felsefe Sözlüğü ise "yaklaşık olarak aynı yıllarda doğmuş, aynı çağın şartlarını, dolayısıyla birbirine benzer sıkıntıları, kaderleri paylaşmış, benzer ödevlerle yükümlü olmuş kişilerin topluluğu" şeklinde tanımlamıştır (www.sozluk.gov.tr). Günümüzde bu kuşaklar farklı davranış kalıpları sergilemektedir. Her kuşağın kendine has özellikleri güçlü ve zayıf yanları bulunmasının yansıra değer yargıları, algıları, düşünceleri, bakış açları, davranışları, tutumları, tercihleri farklılık göstermektedir. Birbirleri ile yakın dönemlerde doğmuş olan bireyler hayatları boyunca benzer toplumsal özellikler göstermekte, benzer olayları yaşamakta ve benzer tercihleri olabilmektedir.

Kuşak kavramını bilimsel çalışmalarında ilk kullanan Alman sosyolog Karl Mannheim olmuştur (Mücevher ve Erdem, 2018). Karl Mannheim kuşaklar konusunda yaptığı sistematik ve kapsamlı çalışmada kuşakları ortak alışkanlıklara ve ortak kültüre sahip olan ve bu değerleri paylaşan insanlar topluluğu olarak tanımlamıştır (Taş, Demirdöğmez ve Küçükoğlu, 2017). Aynı kuşağa ait bireylerin algılarında, tutumlarında, iletişim biçimlerinde, tercihlerinde, beklentilerinde, karar verme süreçlerinde ve satın alma kararlarında benzer özellikler taşıdıkları ifade edilmektedir (Akten, 2016).

Kuşak teorisi, doğum yılları itibariyle benzer politik ve sosyal olayları yaşayan, eşsiz değer yargiları ve inanç sistemlerini bünyelerinde geliştiren, birbirine benzer kişilik özellikleri gösteren bireylerden oluşan bir topluluğu ileri sürmektedir (Ayhün, 2013). Buna göre her kuşağın karakteristik özellikleri, hayata bakışı, değer yargıları, iletişim biçimi, tutumları, davranış tarzı farklılık göstermektedir. Bireyler doğmuş oldukları kuşak grubunun benzer davranış özelliklerini gösterirken diğer kuşak grubunun davranışlarından farklı özellikler sergilemektedirler (Chen, 2010).

Kuşakların sınıflandırılması konusunda literatürde farklı çalışmalar bulunmaktadır. Bu çalışmada ele alınacak sınıflandırma yaygın kabul gören doğum yıllarına göre olan sınıflandırmadır. Bu kuşaklar doğdukları yıla göre; 1965-1979 arasına "X Kuşağı", 1980-1999 arasına "Y Kuşağ1" ve 2000 
yılı sonrasına "Z Kuşağı" olarak tanımlanmıştır (Green, 2006; Taş, Hor ve Keats, 2008; Harpaz ve Snir, 2014; Demirdöğmez ve Küçükoğlu, 2017).

\section{Kuşă̆ı}

1965 ile 1979 yılları arasında doğan bireyleri kapsayan kuşaktır (Kyles, 2005; Sönmez, 2016). X kuşağı ifadesi Douglas Coupland'ın 1991 yılında "Generation X: Tales for an accelerated culture" adlı eserinin yayınlanması ile kullanılmaya başlanmıştır. Yazar etiketlere karşı çıkan kuşağın adını X Kuşağı olarak ifade ederken, sonradan gelen kuşakların $\mathrm{Y}$ ve $\mathrm{Z}$ olarak isimlendirilmesine de zemin hazırlamıştır (Demirkaya, Akdemir, Karaman ve Atan, 2015).

İş hayatındaki çalışanların büyük bir kısmını oluşturan bu kuşak günümüzde Türkiye nüfusunun yaklaşık \%22 kadarın temsil etmektedir. Cesur olmaları aynı zamanda tedbiri de elden bırakmamaları, garantici, tedbirli, eğlenceli, mücadeleci ve dinamik olmaları, marka sadakatinin yüksek olması, cinsiyet eşitliği ile tanışan ilk kuşak olmaları, bağımsız olmayı sevmeleri genel özellikleri arasında gösterilmektedir (Akten, 2016). X kuşağı olabildiğince kanaatkâr, toplumcu, sadık, aidiyet özelliği güçlü, otoriteye saygıllı, idealist, çalışkanlığı ile öne çıkan, toplumsal sorunlara karşı duyarlı, kurallara uyan, iş motivasyonları yüksek bireylerdir (Akten, 2016; Ayhün, 2013; Taş, Demirdöğmez ve Küçükoğlu, 2017). X kuşağında bulunan kişiler küresel düşünen, pragmatist, işlerine bağlı ancak iş ile özel hayat dengesini kurmak için özen gösteren, değişik yaşam tarzlarına ve kültürel çeşitliliğe karşı hoşgörülü, tedbirli ve garanticidirler (Biztatar, 2017).

$\mathrm{X}$ kuşağı hedef odaklı, bağımsız, teknolojiye ve bilgiye karşı istekli yapıdadır. İlk kez kişisel bilgisayarlara erişme imkânı bulan bu kuşak, gelişen teknoloji alışkanlıklarının da alt yapısını oluşturmuştur (Kurtoğlu, Sönmez ve Temiz, 2016). X kuşağındaki bireylerin gelirleri genellikle yüksektir. D1şarıda yemek yeme ve seyahat eğilimleri fazladır (Serçek ve Serçek, 2017).

\section{Y Kuşă̆ı}

1980 ile 1999 yılları arasında doğan bireyler Y kuşağı olarak anılmaktadır (Kyles, 2005). Y kuşağındaki bireyler bilgi iletişim teknolojilerinin geliştiği, internetin yeni ortaya çıtığı bir dönemde dünyaya gelmişlerdir. Teknoloji- 
ye ilgi duyan bu kuşak zamanının büyük bir kısmını bilgisayar, cep telefonu ve internet ile etkileşim içinde geçirmiştir (Kavala ve Ünal, 2016).

Y kuşağı bireyleri; bireyci, istek ve beklentilerini kolaylıkla ortaya koyabilen, girişimci, özgürlüklerine düşkün, teknolojiye merak duyan, istekleri oldukça fazla, sadakat duyguları az, rahatlı̆ı̆na düşkün, eğlenceyi, kazanmayı seven, hırslı, sıradan olanı sevmeyen bireylerdir (Birdir, Toksöz ve Birdir, 2019). Kendilerinden önceki kuşaklara göre daha rahat bir çocukluk yaşamışlardır.

Y kuşağı bireylerinin ebeveynleri, çocukların günlük yaşantılarından alacakları kararlara, aktivitelerinden, planlarına pek çok şeyi ile yakından ilgilenmişlerdir. Y kuşağı bireyleri ebeveynlerinden gördükleri bu destek ile kendilerini daha güvende hissetmekte ve pek çok şeyi başarabileceklerine inanmaktadırlar (Sönmez, 2016). Bu dönemde özel televizyon kanalları yayınlara başlamış, televizyon kanallarında sergilenen batılı yaşam tarzı bireylerin beklenti ve tercihleri üzerinde etkili olmuştur. Yine bu dönemdeki bireyler cep telefonu ve internet ile tanışan ve bu teknolojiler ile büyüyen kuşaktır.

\section{Z Kuşă̆ı}

2000 yılı ve sonrasında dünyaya gelen bireylerdir. Bu kuşaktaki bireyler teknolojinin tam ortasında dünyaya gelmişlerdir ve teknolojiyle iç içe yaşamaktadırlar. Bundan dolayı farklı kaynaklarda dijital kuşak ve internet kuşağı olarak da anılmaktadırlar (Kavalcı ve Ünal, 2016). Z kuşağını diğer kuşaklardan ayıran en belirgin özelliği yüksek teknolojinin yaygın olarak kullanıldığı bir zaman diliminde dünyaya gelmiş olmalarıdır (Taş, Demirdöğmez ve Küçükoğlu, 2017).

Teknoloji sayesinde bilgiye ulaşmaları çok kolaydır. Erken yaşta eğitim almaya başlayan Z kuşağı hızlı zihinsel gelişim göstermektedir (Taş, Demirdöğmez ve Küçükoğlu, 2017). Akıllı cihazlar ile iç içedirler ve sosyal medya araçlarını yaygın biçimde kullanırlar. Klasik oyuncaklar yerine dijital oyun ve oyuncakları tercih ederler.

Birbiri ile sürekli etkileşimde olan $\mathrm{Z}$ kuşağı bireyleri birer dünya vatandaşı gibi yetişmektedirler. Sosyal medyada fotoğraf, video, metin vb. pek çok içerik ile yaşadıkları yerlerdeki olumlu olumsuz tüm gelişmeleri payla- 
şabilmekte, aynı şekilde tüm dünyadaki gelişmelerden haberdar olabilmektedirler (Sönmez, 2016).

Teknoloji bağımlılıkları ve uzaktan iletişim kurmaları nedeniyle yalnız yaşamaya meyilli olabilmektedirler. Teknolojik imkânlar ile büyümeleri nedeniyle motor becerileri ve zekâ düzeylerinin diğer nesillere göre yüksek olduğu tahmin edilmektedir. Teknolojiyi hayatın bir parçası olarak görürler (Okumuş, 2016). Singh Z kuşağının genel özelliklerini; teknik meraklı, erken olgunlaşmış, şımartılmış, güçlendirilmiş, risk karşıtı ve koruma altında olarak açıklamaktadır (Singh, 2014). Tablo 1'de X, Y ve Z kuşaklarının özellikleri ve değerleri karşılaştırmalı olarak verilmiştir.

Tablo 1. X, Y ve Z Kuşaklarmın Özellikleri ve Değerleri

\begin{tabular}{|c|c|c|c|}
\hline Kuşaklar & X Kuşağ1 & Y Kuşağ1 & Z Kuşağı \\
\hline \multirow{17}{*}{$\begin{array}{l}\text { Özellikleri } \\
\text { ve } \\
\text { Değerleri }\end{array}$} & Sadakat duyguları değişken & Sadakat duyguları az & İşbirlikçi \\
\hline & Otoriteye saygilı & Otoriteyi zor kabullenen & Yaratici \\
\hline & Topluma duyarlı & Bağımsızlığına düşkün & Teknoloji içinde doğan \\
\hline & İş motivasyonları yüksek & Çok sık iş değiştiren & Dikkatli ve güvenliğine düşkün \\
\hline & Kanaatkâr & Bireyci & Yeşile ön yargılı ama korumacı \\
\hline & Kaygilı & Teknolojiyle büyüyen & Güvensiz, kimlik arayan \\
\hline & Teknolojiyle ilişkisi düşük & Maceraperest & Tasarruflu para harcayan \\
\hline & Gelirleri yüksek & \multicolumn{2}{|c|}{ Yeşil dostu ama rahatına düşkün $\quad$ Bireysel } \\
\hline & Çocukları giderlere sahip & Yüksek özgüven & Gerçekçi ve pragmatik \\
\hline & $\begin{array}{l}\text { Dışarıda yemek yeme ve } \\
\text { seyahat eğilimleri fazla }\end{array}$ & Para harcamada rahat & Sonuç odaklı \\
\hline & & Aileye bağımlı & Dengeli paylaşan \\
\hline & & İyimser ve ilerici & Teknoloji düşkünü \\
\hline & & Neden odaklı & Teknoloji düşkünü \\
\hline & & Hepsini isteyen & Düşük bütçe ile seyahate çıkan \\
\hline & & Teknolojiye hakim & $\begin{array}{l}\text { Sosyal etkinlik gereksinimleri } \\
\text { oldukça fazla }\end{array}$ \\
\hline & & \multicolumn{2}{|l|}{ Genellikle iki gelire sahip } \\
\hline & & Seyahate fazla eğilimli & \\
\hline
\end{tabular}

Kaynak: (Akten, 2016; Serçek ve Serçek, 2016; Taş, Demirdöğmez ve Küçükoğlu, 2017)

\section{Seyahat Motivasyonu}

Tarih boyunca insanlar çeşitli nedenlerle seyahat etmek durumunda kalmışlardır. Her dönemde insanları seyahate yönelten farklı nedenler var olagelmiştir. Seyahat motivasyonu olarak da açıklanan bu nedenler iş, tatil, sağlık, rahatlama, dinlenme, arkadaş ziyareti, eğitim, yenilik arama, kendini ger- 
çekleştirme, macera arama, eğlence, kültürel deneyim gibi farklı motivasyonlar olabilmektedir.

Seyahat motivasyonu turistlerin destinasyon tercihinde önemli rol oynar (Baloglu ve Uysal, 1996). Turizm alanında çalışan pek çok araştırmacının seyahat motivasyonları konusunda cevap aradıkları önemli sorulardan biri "turist neden seyahat eder" sorusu olmuştur (Cohen, 1972; Jang ve Cai, 2002). Turizmde seyahat motivasyonu konusunda yapılan çalışmalar incelendiğinde yaygin olarak itici (push) ve çekici (pull) seyahat motivasyon teorisi genel kabul görmektedir (Chon, 1989). Crompton, (1979) ve Dann, (1981) ortaya koydukları itici ve çekici faktörler yaklaşımına göre bireyin seyahat etmesinde itici ve çekici motivasyon olarak ifade edilen temel motivasyon faktörleri belirleyici olmaktadır. Buna göre bireyleri seyahate yönelten itici faktörler ile seyahat edecekleri destinasyonda çekici faktörler bulunur. Kişi bu itici ve çekici faktörlere göre seyahate yönelir. Çekici faktörler destinasyona ilişkin özellikleri, doğal ve kültürel varlıkları, destinasyonun niteliklerini ifade eden dışsal faktörleri ifade ederken; itici faktörler ise kişiyi seyahate yönelten, bulunduğu yerden ayrılmasını tetikleyecek daha çok içsel ve psikolojik etmenleri ifade etmektedir.

Bireylerin tatil anlayışlarında, seyahat yeri seçiminde, yeme içme tercihinde ve eğlence anlayışında meydana gelen değişiklikler ile yaşları arasında anlamlı bir ilişki olduğunu ortaya koyan çalışmalar bulunmaktadır (Kotler, Bowen ve Makens, 1999). Dolayısıyla bu farklılıkların göz önünde bulundurulması ve buna uygun pazarlama faaliyetlerinin yürütülmesi hem pazarlamacılar açısından hem de tüketiciler açısından pek çok fayda sağlamaktadır. Bu nedenle bireylerin kuşaklara göre seyahat motivasyonlarının ve seyahat tercihlerinin incelenmesi oldukça önemlidir.

\section{Yöntem}

Araştırmanın temel amacı X, Y ve Z kuşaklarının seyahat motivasyonlarının farklılık gösterip göstermediğini ortaya koymaktır. Bu amaç doğrultusunda araştırmada kullanılan seyahat motivasyonları ölçeği için Jang ve Cai (2002) ile İbiş ve Batman (2018) çalışmalarından faydalanılmıştır. Kolayda örnekleme tekniği ile elde edilen verilere frekans analizi, $t$-testi ve ANOVA testleri uygulanmıştır. Araştırma evrenini tüm X, Y ve Z kuşakları oluşturmaktadır. Örneklemini ise İstanbul ilinde yaşayan tüketiciler oluşturmaktadır. İstan- 
bul ilinden gönüllü katılımcılar ile anket yapılmıştır. Anketlerin bir kısmı elden dağıtılan formlar aracılığı ile bir kısmı ise internet ortamında doldurtulmuştur. Araştırma kapsamında doldurtulan 566 adet anket değerlendirmeye alınmıştır.

Araştırma makalelerinde, buraya yöntem kısmı eklenmeli ve yöntemden sonra varsa, alt başlıklara (ikinci, üçüncü düzey başlıklar) yer verilmelidir.

\section{Bulgular}

Araştırmaya katılanlara ilişkin demografik bilgiler Tablo 2' de verilmiştir.

Tablo 2. Demografik Bilgiler

\begin{tabular}{|c|c|c|}
\hline Cinsiyet & $\mathrm{n}$ & $\%$ \\
\hline Kadın & 309 & 54,6 \\
\hline Erkek & 257 & 45,4 \\
\hline \multicolumn{3}{|l|}{ Medeni Durum } \\
\hline Evli & 184 & 32,5 \\
\hline Bekâr & 382 & 67,5 \\
\hline \multicolumn{3}{|l|}{ Gelir Durumu } \\
\hline $0-1000$ & 197 & 34,8 \\
\hline $1001-2000$ & 62 & 11,0 \\
\hline $2001-3000$ & 83 & 14,7 \\
\hline $3001-4000$ & 93 & 16,4 \\
\hline 4000 ve üzeri & 131 & 23,1 \\
\hline \multicolumn{3}{|c|}{ Ortalama Konaklama } \\
\hline 1-3 Gece & 209 & 36,9 \\
\hline 4-6 Gece & 197 & 34,8 \\
\hline 6 Gece ve üzeri & 160 & 28,3 \\
\hline Yaş (Kuşak) & $\mathrm{n}$ & $\%$ \\
\hline $\mathrm{X}$ & 165 & 29,2 \\
\hline $\mathrm{Y}$ & 196 & 34,6 \\
\hline $\mathrm{Z}$ & 205 & 36,2 \\
\hline \multicolumn{3}{|l|}{ Eğitim Durumu } \\
\hline İköğretim & 204 & 36,0 \\
\hline Lise & 48 & 8,5 \\
\hline Ön lisans & 47 & 8,3 \\
\hline Lisans & 157 & 27,7 \\
\hline Lisansüstü & 110 & 19,4 \\
\hline \multicolumn{3}{|c|}{ Ortalama Harcama } \\
\hline $0-1000$ & 225 & 39,8 \\
\hline $1001-2000$ & 101 & 17,8 \\
\hline $2001-3000$ & 133 & 23,5 \\
\hline 3001 ve üzeri & 107 & 18,9 \\
\hline
\end{tabular}


Buna göre katılımcıların \%54,6'sı kadın, \%45,4'ünün erkeklerden oluştuğu görülmektedir. Kuşaklara göre katılımcı sayılarına bakıldığında \%29,2'sinin X kuşağı, \%34,6'sının Y kuşağı, \%36,2'sinin Z kuşağından oluştuğu görülmektedir. Katılımcıların çoğunluğu bekârlardan oluşurken; gelir durumu 0 ile 1000 TL arasında olanlar \%34,8 ile çoğunluğu oluşturmuştur. Katılımcların seyahatleri esnasında ortalama konaklama süreleri, ortalama harcama tutarları ve eğitim durumları da Tablo 2'de verilmiştir.

Tablo 3. Cinsiyete Göre Kuşakların Dağılımı

\begin{tabular}{|c|c|c|c|c|c|c|}
\hline Cinsiyet & & $\mathrm{X}$ & $Y$ & $\mathrm{Z}$ & Toplam & \\
\hline \multirow[t]{2}{*}{ Kadın } & & & 87 & 94 & 128 & 309 \\
\hline & $\%$ & 15,4 & 16,6 & 22,6 & 54,6 & \\
\hline \multirow[t]{2}{*}{ Erkek } & & & 78 & 102 & 77 & 257 \\
\hline & $\%$ & 13,8 & 18,0 & 13,6 & 45,4 & \\
\hline \multirow[t]{2}{*}{ Toplam } & & & 165 & 196 & 205 & 566 \\
\hline & $\%$ & 29,2 & 34,6 & 36,2 & 100,0 & \\
\hline
\end{tabular}

Araştırma kapsamında katılımcıların kuşaklara göre cinsiyeti frekans ve yüzde olarak Tablo 3'te verilmiştir. Kadınların \%15'i X, \%16's1 Y, \%22'si Z kuşağını oluşturmaktadır. Erkeklerin ise \%13'ü X, \%18'i Y, \%13'ü Z kuşağını oluşturmaktadır.

Tablo 4. Kuşakların Gelir Durumuna Göre Dă̆ılımı

\begin{tabular}{|c|c|c|c|c|c|c|c|}
\hline \multicolumn{2}{|l|}{ Gelir Durumu } & $X$ & $\mathbf{Y}$ & \multirow{2}{*}{\multicolumn{2}{|c|}{$\begin{array}{l}\text { Toplam } \\
49\end{array}$}} & \multirow{3}{*}{130} & \multirow{3}{*}{197} \\
\hline \multirow[t]{2}{*}{$0-1000$} & \multicolumn{2}{|c|}{$\mathrm{f}$} & 18 & & & & \\
\hline & $\%$ & 3,2 & 8,7 & 23,0 & 34,8 & & \\
\hline \multirow[t]{2}{*}{$1001-2000$} & \multicolumn{2}{|c|}{$\mathrm{f}$} & 3 & \multicolumn{2}{|c|}{23} & 36 & 62 \\
\hline & $\%$ & 0,5 & 4,1 & 6,4 & 11,0 & & \\
\hline \multirow[t]{2}{*}{$2001-3000$} & \multicolumn{2}{|c|}{$\mathrm{f}$} & 21 & \multicolumn{2}{|c|}{42} & 20 & 83 \\
\hline & $\%$ & 3,7 & 7,4 & 3,5 & 14,7 & & \\
\hline \multirow[t]{2}{*}{$30001-4000$} & $\mathrm{f}$ & 42 & 40 & 11 & 93 & & \\
\hline & $\%$ & 7,4 & 7,1 & 1,9 & 16,4 & & \\
\hline \multirow[t]{2}{*}{4000 ve üzeri } & \multicolumn{2}{|c|}{$\mathrm{f}$} & 81 & \multicolumn{2}{|c|}{42} & 8 & 131 \\
\hline & $\%$ & 14,3 & 7,4 & 1,4 & 23,1 & & \\
\hline \multirow[t]{2}{*}{ Toplam } & \multicolumn{2}{|c|}{$\mathrm{f}$} & 165 & \multicolumn{2}{|c|}{196} & 205 & 566 \\
\hline & $\%$ & 29,2 & 34,6 & 36,2 & 100,0 & & \\
\hline
\end{tabular}

Tablo 4'te kuşakların gelir durumuna göre dağılımı verilmiştir. X kuşağının gelir durumu incelendiğinde en büyük çoğunluğu \%14 ile 4000 TL ve üzeri grubu oluşturmuştur. Y kuşağında en büyük oran \%8 ile 0-1000 TL grubudur. Z kuşağının gelir durumu incelendiğinde ise en büyük oranı \%23 
ile yine 0-1000 grubu oluşturmuştur. Buna göre gelir durumu en yüksek kuşak X kuşağı, en düşük ise Z kuşağıdır.

Tablo 5. Kuşakların Ortalama Konaklama Sürelerine Göre Dağılımı

\begin{tabular}{lccccccccc}
\hline \multicolumn{2}{c}{ Ortalama Konaklama } & $\mathbf{X}$ & $\mathbf{Y}$ & $\mathbf{Z}$ & \multicolumn{1}{c}{ Toplam } & \\
\hline 1-3 Gece & & $\mathrm{f}$ & & 36 & & 80 & & 93 & 209 \\
& $\%$ & & 6,4 & 14,1 & 16,4 & & 36,9 & & 197 \\
\hline 4-6 Gece & & $\mathrm{f}$ & & 81 & & 79 & & 37 & 160 \\
& $\%$ & & 14,3 & 14,0 & 6,5 & & 34,8 & & \\
\hline 6 Gece ve üzeri & & $\mathrm{f}$ & & 48 & & 37 & & 75 & $\mathbf{5 6 6}$ \\
& $\%$ & & 8,5 & 6,5 & 13,3 & & 28,3 & & \\
\hline Toplam & & $\mathrm{f}$ & & $\mathbf{1 6 5}$ & & $\mathbf{1 9 6}$ & & $\mathbf{2 0 5}$ & \\
& $\%$ & & $\mathbf{2 9 , 2}$ & $\mathbf{3 4 , 6}$ & $\mathbf{3 6 , 2}$ & & $\mathbf{1 0 0 , 0}$ & & \\
\hline
\end{tabular}

Tablo 5'te kuşakların seyahatlerinde ortalama konaklama sürelerine göre dağılımları verilmiştir. Buna göre X kuşağının çoğunluğu (\%14) 4 ile 6 gece arası konaklamaktadır. Y kuşağının ise \%14'ü 1-3 gece arası, \%14'ü de 4-6 gece arası konaklama yaptıkları görülmektedir. $Z$ kuşağında ise en yüksek oran $\% 36$ ile 1-3 gece arasidır.

Tablo 6. Kuşakların Ortalama Harcama Tutarlarına Göre Dağılımı

\begin{tabular}{|c|c|c|c|c|c|c|c|}
\hline \multicolumn{2}{|c|}{ Ortalama Harcama } & $X$ & $\mathbf{Y}$ & \multicolumn{3}{|c|}{ Toplam } & \multirow{3}{*}{225} \\
\hline \multirow[t]{2}{*}{$0-1000$} & \multicolumn{2}{|c|}{$\mathrm{f}$} & 27 & \multicolumn{2}{|c|}{54} & 144 & \\
\hline & $\%$ & 4,8 & 9,5 & 25,4 & 39,8 & & \\
\hline \multirow[t]{2}{*}{$1001-2000$} & \multicolumn{2}{|c|}{$\mathrm{f}$} & 18 & \multicolumn{2}{|c|}{55} & 28 & 101 \\
\hline & $\%$ & 3,2 & 9,7 & 4,9 & 17,8 & & \\
\hline \multirow[t]{2}{*}{$2001-3000$} & \multicolumn{2}{|c|}{$\mathrm{f}$} & 66 & \multicolumn{2}{|c|}{48} & 19 & 133 \\
\hline & $\%$ & 11,7 & 8,5 & 3,4 & 23,5 & & \\
\hline \multirow[t]{2}{*}{3001 ve üzeri } & \multicolumn{2}{|c|}{$\mathrm{f}$} & 54 & \multicolumn{2}{|c|}{39} & 14 & 107 \\
\hline & $\%$ & 9,5 & 6,9 & 2,5 & 18,9 & & \\
\hline \multirow[t]{2}{*}{ Toplam } & \multicolumn{2}{|c|}{$\mathrm{f}$} & 165 & \multicolumn{2}{|c|}{196} & 205 & 566 \\
\hline & $\%$ & 29,2 & 34,6 & 36,2 & 100,0 & & \\
\hline
\end{tabular}

Tablo 6'da kuşakların seyahatleri esnasında ortalama harcama tutarları verilmiştir. En yüksek harcama oranın X kuşağında 2001-3000 grubunda \%11 olduğu görülmüştür. Yine 3001 ve üzeri harcamada en yüksek oranı $X$ kuşağı oluşturmuştur (\%9). Z kuşağının ise en yüksek oranı \%25 ile 0-1000 grubu oluşturmuştur. Buradan çıkan sonuca göre en fazla ortalama harcamayı yapan $X$ kuşağıdır. 
Seyahat Motivasyonlarının X, Y ve Z Kuşaklarına Göre Farklılıklarının İncelenmesi Üzerine Bir Araştırma

Tablo 7. İtici Seyahat Motivasyonlarna İlişkin Faktör Analizi Sonuçlar

\begin{tabular}{|c|c|c|c|c|c|}
\hline \multicolumn{5}{|l|}{ Faktör Boyutları } & \multirow{3}{*}{$\begin{array}{l}\text { Faktör } \\
\text { Yükü }\end{array}$} \\
\hline \multirow{2}{*}{ Rahatlamak } & Aç. Varyans & Özdeğer & Art. Ort. & Cr. Alfa & \\
\hline & 49,503 & 7,425 & 2,097 & 0,912 & \\
\hline \multicolumn{5}{|c|}{ S14 Günlük rutin hayattan uzaklaşmak için seyahat ederim } & 0,812 \\
\hline \multicolumn{5}{|c|}{ S12 Zihinsel olarak rahatlamak için seyahat ederim } & 0,802 \\
\hline \multicolumn{5}{|c|}{ S15 Yoğun iş temposundan kaçmak için seyahat ederim } & 0,792 \\
\hline \multicolumn{5}{|c|}{ S13 Fiziksel olarak rahatlamak için seyahat ederim } & 0,780 \\
\hline \multicolumn{5}{|c|}{ S16 Sakin bir atmosferde bulunmak için seyahat ederim } & 0,741 \\
\hline \multirow{2}{*}{ Yenilik Aramak } & Aç. Varyans & Özdeğer & Art. Ort. & Cr. Alfa & \\
\hline & 10,097 & 1,514 & 2,427 & 0,853 & \\
\hline \multicolumn{5}{|c|}{ S9 Yeni şeyler öğrenmek için seyahat ederim } & 0,758 \\
\hline \multicolumn{5}{|c|}{ S10 Bilgimi arttırmak için seyahat ederim } & 0,738 \\
\hline \multicolumn{5}{|c|}{ S11 Yeni insanlar tanımak için seyahat ederim } & 0,736 \\
\hline \multicolumn{5}{|c|}{ S8 Yeni tatlar denemek için seyahat ederim } & 0,698 \\
\hline \multirow{2}{*}{ Keşif } & Aç. Varyans & Özdeğer & Art. Ort. & Cr. Alfa & \\
\hline & 8,484 & 1,273 & 2,525 & 0,875 & \\
\hline \multicolumn{5}{|c|}{ S21 Cesur ve maceracı olmak için seyahat ederim } & 0,893 \\
\hline \multicolumn{5}{|c|}{ S22 Heyecan verici deneyimler yaşamak için seyahat ederim } & 0,828 \\
\hline \multicolumn{5}{|c|}{ S20 Kendimi yeniden keşfetmek için seyahat ederim } & 0,682 \\
\hline \multirow{2}{*}{$\begin{array}{l}\text { Yakınlar Akrabalar ile } \\
\text { Olmak }\end{array}$} & Aç. Varyans & Özdeğer & Art. Ort. & Cr. Alfa & \\
\hline & 6,523 & 1.026 & 2,252 & 0,744 & \\
\hline \multicolumn{5}{|c|}{ S23 Akrabalarımı ziyaret etmek için seyahat ederim } & 0,881 \\
\hline \multicolumn{5}{|c|}{ S26 Ailem ile birlikte iyi vakit geçirmek için seyahat ederim } & 0,773 \\
\hline \multicolumn{5}{|c|}{ S25 Arkadaşlarım ile birlikte iyi vakit geçirmek için seyahat ederim } & 0,554 \\
\hline
\end{tabular}

Varimaks Rotasyonlu Temel Bileşenler Analizi: Açıklanan Toplam Varyans: \% 74,707; Kaiser-Meyer-Olkin Örneklem Yeterliliği: 0,906; Bartlett's Küresellik Testi: p<0,001; KiKare: 5620,149; Sig. ,000; df:105; Cronbach's Alpha: 0,923

Tablo 7'de itici seyahat motivasyonlarına ilişkin faktör analizi sonuçlarına yer verilmiştir. Buna göre itici seyahat motivasyonlarının dört boyuttan oluştuğu görülmektedir. İtici seyahat motivasyonları faktör analizinde açılanan toplam varyans \%74, KMO 0,906 ve Cronbach's Alpha 0,923 olarak hesaplanmıştır. Tabloda her boyut için açıklanan varyans, özdeğer, her boyutun aritmetik ortalaması, güvenirlik ve faktör yükü değerleri verilmiştir. 
Tablo 8. Çekici Seyahat Motivasyonlarna İlişkin Faktör Analizi Sonuçlar

\begin{tabular}{|c|c|c|c|c|c|}
\hline \multicolumn{5}{|l|}{ Faktör Boyutları } & \multirow{3}{*}{$\begin{array}{l}\text { Faktör } \\
\text { Yükü }\end{array}$} \\
\hline \multirow{2}{*}{ Doğal ve Kültürel Olanaklar } & Aç. Varyans & Özdeğer & Art. Ort. & Cr. Alfa & \\
\hline & 42,618 & 9,376 & 2,059 & 0,905 & \\
\hline \multicolumn{5}{|l|}{ S29 Kültürel varlıkların olması } & 0,806 \\
\hline \multicolumn{5}{|l|}{ S30 Doğal manzaraların olması } & 0,777 \\
\hline \multicolumn{5}{|c|}{ S32 Bozulmamış ve kirlenmemiş çevrenin olması } & 0,767 \\
\hline \multicolumn{5}{|c|}{ S31 Elverişli iklimin olması } & 0,765 \\
\hline \multicolumn{5}{|l|}{ S28 Arkeolojik yerlerin olması } & 0,716 \\
\hline \multicolumn{5}{|c|}{ S27 Doğal park ve ormanların olması } & 0,635 \\
\hline \multirow{2}{*}{ Kalite ve Güven } & Aç. Varyans & Özdeğer & Art. Ort. & Cr. Alfa & \\
\hline & 11,289 & 2,484 & 1,845 & 0,968 & \\
\hline \multicolumn{5}{|c|}{ S44 Kaliteli konaklama imkânları olması } & 0,869 \\
\hline \multicolumn{5}{|c|}{ S43 Kaliteli yeme içme olanakları olması } & 0,862 \\
\hline \multicolumn{5}{|c|}{ S42 Güvenilir bir yer olması } & 0,861 \\
\hline \multicolumn{5}{|c|}{ S41 Standart hijyen ve temizlik koşulları olması } & 0,845 \\
\hline \multirow{2}{*}{ Fiyat ve Uygunluk } & Aç. Varyans & Özdeğer & Art. Ort. & Cr. Alfa & \\
\hline & 10,100 & 2,222 & 3,213 & 0,969 & \\
\hline \multicolumn{5}{|c|}{ S38 Ulaşım olanaklarının uygunluğu } & 0,920 \\
\hline \multicolumn{5}{|c|}{ S39 Konaklama imkânlarının çeşitliliği } & 0,913 \\
\hline \multicolumn{5}{|c|}{ S37 Uygun fiyata konaklama imkânlarının bulunması } & 0,905 \\
\hline \multicolumn{5}{|c|}{ S40 Ödemiş olduğum paranın karşılığını alabilme } & 0,897 \\
\hline \multirow{2}{*}{ Alışveriş Olanakları } & Aç. Varyans & Özdeğer & Art. Ort. & Cr. Alfa & \\
\hline & 8,782 & 1,932 & 2,810 & 0,882 & \\
\hline \multicolumn{5}{|c|}{ S45 Alışveriş merkezlerinin bulunması } & 0,896 \\
\hline \multicolumn{5}{|c|}{ S47 Marka ürünlerin bulunması } & 0,872 \\
\hline \multicolumn{5}{|c|}{ S46 Alışveriş olanaklarının fazla olması } & 0,845 \\
\hline \multicolumn{5}{|c|}{ S48 Yaşadığım yerden daha ucuza alışveriş imkanı olması } & 0,662 \\
\hline \multirow{2}{*}{ Etkinlikler } & Aç. Varyans & Özdeğer & Art. Ort. & Cr. Alfa & \\
\hline & 5,253 & 1,156 & 2,742 & 0,789 & \\
\hline \multicolumn{5}{|c|}{ S36 Rekreasyonel faaliyetlere katılmak } & 0,822 \\
\hline \multicolumn{5}{|c|}{ S34 Kongre, toplantı ve etkinliklere katılmak } & 0,760 \\
\hline \multicolumn{5}{|c|}{ S35 Yerel festivallere katilmak } & 0,705 \\
\hline \multicolumn{5}{|l|}{ S33 Sportif faaliyetlere katılmak } & 0,556 \\
\hline
\end{tabular}

Varimaks Rotasyonlu Temel Bileşenler Analizi: Açıklanan Toplam Varyans: \% 78,043; Kaiser-Meyer-Olkin Örneklem Yeterliliği: 0,907; Bartlett's Küresellik Testi: p<0,001; KiKare: 11807,295; Sig. ,000; df:231; Cronbach's Alpha: 0,806

Tablo 8'de çekici seyahat motivasyonlarına ilişkin faktör analizi sonuçları yer almaktadır. Toplam açılanan varyans \%78, KMO değeri 0,907 ve Cronbach's Alpha 0,806 olarak belirlenmiştir. 
Tablo 9. Seyahat Motivasyonlarının Kuşaklara Göre Farklılı̆̆ı ANOVA Analizi

\begin{tabular}{|c|c|c|c|c|c|c|}
\hline Seyahat Motivasyonu Boyutları & Kuşak & $\mathbf{N}$ & A.O & $\mathbf{F}$ & Sig & Anlamlı Fark \\
\hline \multirow{3}{*}{ Rahatlamak (IF) } & $\mathrm{X}$ & 165 & 1.810 & \multirow{3}{*}{54.778} & \multirow{3}{*}{0.000} & \multirow{3}{*}{$\begin{array}{l}\mathrm{X}<\mathrm{Z} \\
\mathrm{Y}<\mathrm{Z}\end{array}$} \\
\hline & $\mathrm{Y}$ & 196 & 1.729 & & & \\
\hline & $\mathrm{Z}$ & 205 & 2.678 & & & \\
\hline \multirow{3}{*}{ Yenilik Aramak (IF) } & $x$ & 165 & 2.354 & \multirow{3}{*}{10.307} & \multirow{3}{*}{0.000} & \multirow{3}{*}{$\mathrm{Y}<\mathrm{Z}$} \\
\hline & $\mathrm{Y}$ & 196 & 2.220 & & & \\
\hline & $\mathrm{Z}$ & 205 & 2.681 & & & \\
\hline \multirow{3}{*}{ Keşif (IF) } & $x$ & 165 & 2.551 & \multirow{3}{*}{5.232} & \multirow{3}{*}{0.006} & \multirow{3}{*}{$\mathrm{Y}<\mathrm{Z}$} \\
\hline & $\mathrm{Y}$ & 196 & 2.323 & & & \\
\hline & $\mathrm{Z}$ & 205 & 2.697 & & & \\
\hline \multirow{3}{*}{$\begin{array}{l}\text { Yakınlar, Akrabalar ile Olmak } \\
\text { (IF) }\end{array}$} & $X$ & 165 & 2.266 & \multirow{3}{*}{1.261} & \multirow{3}{*}{0.284} & \multirow{3}{*}{ Yok } \\
\hline & $\mathrm{Y}$ & 196 & 2.328 & & & \\
\hline & $\mathrm{Z}$ & 205 & 2.167 & & & \\
\hline \multirow{3}{*}{ Doğal ve Kültürel Olanaklar (CF) } & $x$ & 165 & 1.857 & \multirow{3}{*}{10.696} & \multirow{3}{*}{0.000} & \multirow{3}{*}{$\begin{array}{l}\mathrm{X}<\mathrm{Z} \\
\mathrm{Y}<\mathrm{Z}\end{array}$} \\
\hline & $\mathrm{Y}$ & 196 & 1.970 & & & \\
\hline & $\mathrm{Z}$ & 205 & 2.307 & & & \\
\hline \multirow{3}{*}{ Kalite ve Güven (CF) } & $x$ & 165 & 1.754 & \multirow{3}{*}{1.920} & \multirow{3}{*}{0.148} & \multirow{3}{*}{ Yok } \\
\hline & $\mathrm{Y}$ & 196 & 1.785 & & & \\
\hline & Z & 205 & 1.974 & & & \\
\hline \multirow{3}{*}{ Fiyat ve Uygunluk (CF) } & $\mathrm{X}$ & 165 & 3.600 & \multirow{3}{*}{9.129} & \multirow{3}{*}{0.000} & \multirow{3}{*}{$X>Z$} \\
\hline & $\mathrm{Y}$ & 196 & 3.177 & & & \\
\hline & $\mathrm{Z}$ & 205 & 2.936 & & & \\
\hline \multirow{3}{*}{ Alışveriş Olanakları (CF) } & $X$ & 165 & 2.859 & \multirow{3}{*}{15.564} & \multirow{3}{*}{0.000} & \multirow{3}{*}{$\begin{array}{l}X>Z \\
Y>Z\end{array}$} \\
\hline & $\mathrm{Y}$ & 196 & 3.103 & & & \\
\hline & $\mathrm{Z}$ & 205 & 2.489 & & & \\
\hline & $x$ & 165 & 2.522 & & & \\
\hline Etkinlikler (CF) & $\mathrm{Y}$ & 196 & 2.815 & 6.425 & 0.002 & $\begin{array}{l}X<Y \\
X<7\end{array}$ \\
\hline & $\mathrm{Z}$ & 205 & 2.850 & & & $X<Z$ \\
\hline
\end{tabular}

Tablo 9'da itici ve çekici seyahat motivasyonlarının kuşaklara göre farkl1lık gösterip göstermediğini test etmek amacı ile yapılan ANOVA analizi sonuçları yer almaktadır. Buna göre; itici seyahat motivasyonlarından yakınlar akrabalar ile birlikte olmak boyutu ile çekici seyahat motivasyonlarından kalite ve güven boyutunda kuşaklara göre anlamlı bir farklılığın olmadığ görülmüş̧ür.

İtici seyahat motivasyon boyutlarından rahatlamak boyutunda kuşaklar arasında anlamlı bir farklılığın olduğu tespit edilmiştir. Bu farklılığın $X$ ile $Z$ ve $\mathrm{Y}$ ile $\mathrm{Z}$ kuşakları arasında olduğu tespit edilmiştir. Buna göre $\mathrm{Z}$ kuşağının hem $X$ kuşağına göre hem de $Y$ kuşağına göre daha fazla rahatlama amaçlı seyahat ettiği söylenebilir.

Yenilik arama boyutunda anlamlı farklılık Y ile Z kuşakları arasında olduğu tespit edilmiştir. Buna göre $Z$ kuşağının $Y$ kuşağına göre daha fazla 
yenilik arama amaçlı seyahat etmektedir yorumu yapılabilir. Benzer şekilde keşif boyutunda da Z kuşağı $Y$ kuşağına göre daha fazla keşif amaçlı seyahat etmektedir.

Çekici motivasyonlara bakıldığında doğal ve kültürel olanaklar boyutunda $X$ ile $Z$ ve $Y$ ile $Z$ kuşakları arasında anlamlı farklılıkların olduğu görülmüsstür. $Z$ kuşağı hem $X$ kuşağına göre hem de $Y$ kuşağına göre daha fazla doğal ve kültürel olanakları olan yerleri tercih etmektedir.

Fiyat ve uygunluk boyutunda ise anlamlı farklılık X ile Z kuşakları arasında görülmüştür. $\mathrm{Bu}$ da $\mathrm{X}$ kuşağının fiyat ve uygunluğu $\mathrm{Z}$ kuşağına göre daha fazla önemsediğini göstermiştir. Alışveriş olanakları boyutunda anlamlı farklılık $X$ ile $Z$ ve $Y$ ile $Z$ kuşakları arasında görülmüştür. $X$ ve $Y$ kuşaklarının $Z$ kuşağına göre alışveriş olanaklarını önemsedikleri anlaşılmaktadır. Son olarak etkinlikler boyutu incelendiğinde anlamlı farklılık $X$ ile $Y$ ve $X$ ile $Z$ kuşakları arasında olduğu görülmüştür. $B u$ da $Y$ ve $Z$ kuşaklarının $X$ kuşağına göre seyahat edilen yerlerde etkinliklerin olmasını önemsediklerini göstermiştir.

Tablo 10. Seyahat Motivasyon Faktörlerinin Kuşaklara Göre Dağılımı

\begin{tabular}{lllllll}
\hline \multirow{2}{*}{ Faktörler } & \multicolumn{2}{c}{ X Kuşağı } & \multicolumn{2}{c}{ Y Kuşă̆ } & \multicolumn{2}{c}{ Z Kuşağı } \\
\cline { 2 - 7 } & A.O & S.S. & A.O & S.S. & A.O & S.S. \\
\hline Rahatlamak (IF) & 1.810 & 0.942 & 1.729 & 0.986 & $\mathbf{2 . 6 7 8}$ & 1.051 \\
\hline Yenilik Aramak (IF) & 2.354 & 1.127 & 2.220 & 0.896 & $\mathbf{2 . 6 8 1}$ & 1.106 \\
\hline Keşif (IF) & 2.551 & 1.272 & 2.323 & 1.068 & $\mathbf{2 . 6 9 7}$ & 1.164 \\
\hline Yakınlar Akrabalar ile Olmak (IF) & 2.266 & 1.093 & $\mathbf{2 . 3 2 8}$ & 0.991 & 2.167 & 0.992 \\
\hline Doğal ve Kültürel Olanaklar (CF) & 1.857 & 0.971 & 1.970 & 0.868 & $\mathbf{2 . 3 0 7}$ & 1.102 \\
\hline Kalite ve Güven (CF) & 1.754 & 1.235 & 1.785 & 1.120 & $\mathbf{1 . 9 7 4}$ & 1.226 \\
\hline Fiyat ve Uygunluk (CF) & $\mathbf{3 . 6 0 0}$ & 1.506 & 3.177 & 1.584 & 2.936 & 1.384 \\
\hline Alişveriş Olanakları (CF) & 2.859 & 1.158 & $\mathbf{3 . 1 0 3}$ & 1.141 & 2.489 & 1.038 \\
\hline Etkinlikler (CF) & 2.522 & 1.051 & 2.815 & 0.883 & $\mathbf{2 . 8 5 0}$ & 0.898 \\
\hline
\end{tabular}

Tablo 10' da seyahat motivasyonları boyutlarının kuşaklara göre aritmetik ortalamaları ve standart sapmalarına yer verilmiştir. Aritmetik ortalamalara bakıldığında; Z kuşağının rahatlamak, yenilik aramak, keşif, doğal ve kültürel olanaklar, kalite ve güven ile etkinlikler boyutlarına yüksek katılım sağladıkları görülmüsşür. Y kuşağının yüksek katılım gösterdiği boyutlar, yakınlar, akrabalar ile birlikte olmak ve alışveriş olanaklarıdır. X kuşağının en yüksek katılım gösterdiği boyut ise fiyat ve uygunluk olmuştur. 


\section{Tartışma ve Sonuç}

Kuşak konusu ile ilgili literatür incelendiğinde kuşaklara yönelik farklı açılardan ele alınmış pek çok çalışmanın yapıldığını görmek mümkündür. Mücevher ve Erdem (2018) X kuşağı akademisyenler ile Y kuşağı öğrencilerinin birbirlerine karşı algılarını inceleyen çalışma yapmıştır. Taşova (2019) $X$ ve $Y$ kuşaklarının bireysel değerleri, iş değerleri ve motivasyonları ile örgütsel bağlılıkları arasındaki ilişkiyi araştırdığı çalışmada bireysel değerler motivasyon ile örgütsel bağllık alt boyutlarda anlamlı bir ilişki olduğunu ortaya koymuştur. Kavalcı (2015) yaptığı çalışma sonucuna göre $Y$ ve $Z$ kuşaklarının öğrenme stilleri ve satın alma tarzları arasında farklılık olduğunu saptamıştır. Akten (2016) yaptığı araştırmada Y ve Z kuşaklarının turizmi sosyo-kültürel ve çevresel boyutları açısından farklı algıladıkları, $Y$ kuşağının $Z$ kuşağına kıyasla yaş ve tecrübe olarak turizm algısının daha fazla olduğu kanısına varmıştır. Serçek ve Serçek (2017), X, Y ve Z kuşaklarındaki turistlerin destinasyon imaj algılarının karşılaştırılmasına yönelik yaptıkları araştırma sonuçlarında; destinasyon imajının katılımcıların bulundukları kuşak gruplarına göre farklılık gösterdiğini ortaya koymuşlardır. $\mathrm{Bu}$ çalışmada ise konu turizmde seyahat motivasyonu açısından ele alınmış, seyahat motivasyonlarının kuşaklara göre farklılıkları incelenmiş ve bulgulardan yola çıkarak bazı çıkarımlar elde edilmiştir. Yaş faktörünün önemli bir pazar bölümlendirme kriteri olarak kabul gördüğü düşünüldüğünde bu çalışmanın sonucunda ortaya çkan bulgular, seyahat pazarlamasına yönelik önemli ipuçları vermektedir.

Birbirine yakın oranlarda $X, Y$ ve $Z$ kuşaklarından katılımcların dâhil edildiği bu çalışmada kuşakların seyahat motivasyonlarına ilişkin bazı önemli bulgular elde edilmiştir. Araştırma sonuçları $X$ kuşağının gelir durumlarının $\mathrm{Y}$ ve $\mathrm{Z}$ kuşaklarına göre daha yüksek olduğunu göstermiştir. Kuşakların ortalama harcama tutarlarına bakıldığında ise en fazla harcamayı $X$ kuşağının, en düşük harcamayı ise $Z$ kuşağının yaptığı görülmüştür. Bu sonuçlar $X$ kuşağının ileri yaşta, meslek sahibi olması nedeni ve belli bir gelir düzeyine sahip olması ile açılanabilir. Genç nüfustan oluşan Z kuşağının ise iş ve meslek hayatına yeni dâhil olacak olması ve henüz gelir durumunun kısıtlı olması kuşağın, harcama düzeylerinin de düşük görünmesine neden olmaktadir. 
Katılımcların itici seyahat motivasyonları 4 boyuttan, çekici seyahat motivasyonları ise 3 boyuttan oluşmuştur. Boyutların kuşaklara göre bazı farklılıkları olduğu tespit edilmiştir. Burada öne çıkan bulgu Z kuşağının daha fazla rahatlama, yenilik arama, keşif amaçlı seyahat etme isteğinde olmasıdır. Bir diğer önemli sonuç Z kuşağının hem X hem de $Y$ kuşağına göre daha fazla doğal ve kültürel olanaklardan faydalanma eğilimi göstermesidir. Ayrıca $X$ ve $Y$ kuşaklarının $Z$ kuşağına göre alışveriş olanaklarını daha fazla önemsedikleri anlaşılmıştır.

Kuşaklar, en yüksek katılım gösterdikleri seyahat motivasyonları açısından değerlendirildiğinde $X$ kuşağının fiyat ve uygunluğu önemsediği; $Y$ kuşağının yakınlar, akrabalar ile birlikte olmayı ve alışveriş olanaklarını önemsediği; Z kuşağının ise rahatlama, yenilik arama, keşif, doğal ve kültürel olanaklar, kalite ve güven ile etkinlik olanaklarını önemsediği anlaşılmıştır. Dolayısıyla yapılacak pazarlama faaliyetlerinde potansiyel müşterilerin kuşaklara göre sınıflandırılması ve ardından her kuşağın öne çıkan ilgi ve beklentileri doğrultusunda ürün ve hizmet tasarımına gidilmesi hem işletmeler için hem de müşteriler için büyük fayda sağlayacaktır. Gelecekte Z kuşağının en büyük potansiyel turist grubunda yer alacağı düşünüldüğünde turistik ürün ve hizmetlerin $Z$ kuşağının ilgi ve beklentilerine uygun olarak tasarlanması son derece önemli olacaktır. Yine özellikle $Z$ kuşağına yönelik yapılacak araştırmalar hem literatür hem de sektör açısından önem taşıyacaktır. 


\title{
EXTENDED ABSTRACT
}

\section{A Study on Investigation of Differences of Travel Motivations According to X, Y and Z Generations}

\author{
Serdar Çöp -Salim İbiş -Özgür Kızıldemir \\ İstanbul Gelişim University, İstanbul Galata University
}

The aim of this research; To examine whether the travel motivations of the $\mathrm{X}, \mathrm{Y}$ and $\mathrm{Z}$ generations differ. In line with this purpose, 566 people, including participants from all generations, were reached with the convenience sampling technique and filled out a questionnaire about their travel motivation. The data obtained were analyzed by quantitative analysis techniques. As a result of the analysis, it was seen that travel motivations, which consist of seven dimensions, differ according to generations.

Considering the $\mathrm{X}, \mathrm{Y}$ and $\mathrm{Z}$ generations as today's tourist profile, it is necessary to know their general characteristics, to understand the preferences of travel, accommodation, eating and drinking, and to create products and services accordingly. In this study, it was aimed to determine the travel motivations of generations and to examine the differences of travel motivations according to generations. The findings resulting from the analysis made with the data obtained were explained. It is thought that the results of the study will contribute to both the tourism literature and tourism marketers.

Changes in social, economic and technological areas in the society have an effect on many issues such as people's value judgments, attitudes, behavior styles and lifestyles. Increasing competition conditions make it necessary to examine in-depth consumer behavior and make special researches on the preferences of consumers obligatory (Kotler and Armstrong, 2004). Factors such as globalization, social change, and widespread use of technology have significant effects on people's lifestyle, wishes and expectations. Tourism preferences are also affected by these factors. One of the methods used in the creation of market segments for tourists in the tourism industry is the method of market segmentation according to generations. Considering that each generation has different wishes, desires and expectations and this af- 
fects the purchasing behaviors, such segmentation provides many advantages to the marketing field (Serçek and Serçek, 2017).

German sociologist Karl Mannheim was the first to use the concept of generation in his scientific studies (Mücevher and Erdem, 2018). Karl Mannheim, in his systematic and comprehensive study on generations, defined generations as a community of people who share common habits and common culture and share these values (Taş, Demirdöğmez and Küçükoğlu, 2017). It is stated that individuals belonging to the same generation have similar characteristics in their perceptions, attitudes, communication styles, preferences, expectations, decision-making processes and purchasing decisions (Akten, 2016). There are different studies in the literature on the classification of generations. The classification to be dealt with in this study is the classification according to the widely accepted birth years. These generations according to the year they were born; It was defined as "Generation X" between 1965-1979, "Generation Y" between 1980-1999, and "Generation Z" between 2000 and later (Green, 2006; Taş, Hor and Keats, 2008; Harpaz and Snir, 2014; Demirdöğmez and Küçükoğlu, 2017).

Travel motivation plays an important role in tourists' choice of destination (Baloglu and Uysal, 1996). One of the important questions that many researchers working in the field of tourism have sought answers to about their travel motivations has been the question "why does a tourist travel?" (Cohen, 1972; Jang \& Cai, 2002). When the studies on travel motivation in tourism are examined, the push and pull travel motivation theory is widely accepted (Chon, 1989). Crompton, (1979) and Dann (1981), according to the push and pull factors approach, the basic motivation factors, which are expressed as driving and attractive motivation, are determinant in the individual's travel.

The main purpose of the study is to reveal whether the travel motivations of the $\mathrm{X}, \mathrm{Y}$ and $\mathrm{Z}$ generations differ. For this purpose, the studies of Jang and Cai (2002), İbiş and Batman (2018) were used for the travel motivation scale used in the study. Frequency analysis, t-test and ANOVA tests were applied to the data obtained by convenience sampling technique.

According to the results of the factor analysis related to travel motivations, it is seen that driving travel motivations consist of four dimensions. The total variance explained in the driving travel motivations factor analysis was calculated as 74\%, KMO 0.906 and Cronbach's Alpha 0.923. Table 8 
contains the factor analysis results regarding attractive travel motivations. The total explained variance was $78 \%$, KMO value was 0.907 and Cronbach's Alpha was 0.806. Table 9 contains the results of ANOVA analysis to test whether the driving and attractive travel motivations differ according to generations. According to this; It was observed that there was no significant difference between generations in terms of being with relatives, relatives, which are impulsive travel motivations, and quality and trust, from attractive travel motivations.

In Table 10, arithmetic averages and standard deviations of the dimensions of travel motivation according to generations are given. Looking at the arithmetic means; It has been observed that the generation $\mathrm{Z}$ has high participation in the dimensions of activities with relaxation, seeking innovation, exploration, natural and cultural opportunities, quality and trust. The dimensions in which the generation $\mathrm{Y}$ has a high participation are relatives, being with relatives and shopping opportunities. The dimension with the highest participation of the $X$ generation is price and availability.

In this study, in which participants from the $\mathrm{X}, \mathrm{Y}$ and $\mathrm{Z}$ generations were included in close proportions, some important findings were obtained regarding the travel motivations of the generations. The research results showed that the income status of the $\mathrm{X}$ generation is higher than the $\mathrm{Y}$ and $\mathrm{Z}$ generations. When the average expenditure amounts of the generations are examined, it is seen that the $X$ generation has the highest expenditure and the $\mathrm{Z}$ generation has the lowest. These results can be explained by the fact that the generation $X$ is old, has a profession and has a certain income level. The fact that the generation $\mathrm{Z}$, which consists of young population, will be newly included in business and professional life and the income situation is limited yet causes the spending levels of the generation to appear low.

\section{Kaynakça / References}

Akten, M. (2016). Y ve Z kuşaklarmnn turizm algıları ve konaklama işletmelerinden beklentileri. Yüksek lisans tezi. Balıkesir Üniversitesi Sosyal Bilimler Enstitüsü. DSpace@Balıkesir Kurumsal Akademik Arşiv Sistemi. Balıkesir.

Ayhün, S. E. (2013). Kuşaklar arasındaki farklılıklar ve örgütsel yansımaları. Ekonomi ve Yönetim Araştırmaları Dergisi, 2(1), 93-112. 
Baloglu, S., Uysal, M. (1996). Market segments of push and pull motivations: a Canonical correlation approach. International Journal of Contemporary Hospitality Management, 8(3), 32-38.

Birdir, S. S., Toksöz, D., ve Birdir, K. (2019). Yeşil yıldız uygulamaları: Y kuşağı örneği. Journal of Tourism Theory and Research, 5(2), 123-133.

Biztatar, H. (2017). Olumsuz elektronik ağızdan ağıza pazarlama iletişimine etki eden faktörler: Z kuşağı tüketicilerinin görüşlerini belirlemeye yönelik bir araştırma. Yüksek lisans tezi, Çağ Üniversitesi Sosyal Bilimler Enstitüsü. DSpace@ÇAĞ Kurumsal Akademik Arşiv Sistemi. Mersin.

Chen, H. (2010). Advertising and generational identity: A theoretical model. American Academy of Advertising Conference Proceedings, 132-140.

Chon, K. S. (1989). Understanding Recreational traveler's motivation, attitude and satisfaction. Tourism Review, 44(1), 3-7.

Cohen, E. (1972). Towards sociology of international tourism. Social Research, 23(2), 221-232.

Crompton, J. L. (1979). Motivations for pleasure vacation. Annals of Tourism Research, 6(4), 408-424.

Dann, G. (1981). Tourist motivation an appraisal. Annals of Tourism Research, 8(2), 187-219.

Demirkaya, H., Akdemir, A., Karaman, E., ve Atan, Ö. (2015). Kuşakların yönetim politikası beklentilerinin araştırılması. Journal of Business Research Turk, 7(1), 186-204.

Green, B. (2006). Marketing to leading-edge baby boomers: Perceptions, principles, practices, predictions. New York, ABD: Paramount Market Publishing.

Harpaz, I., Snir, R. (2014). Heavy work investment: Its nature, sources, outcomes, andfuture directions. New York, ABD: Routledge Publishing.

Hor, J., ve Keats, L. (2008). Finders keepers: How to attract and retain great employees. United States: Aspen Publishers, Inc.

İbiş, S., ve Batman, O. (2018). Türkiye'ye gelen Çinli turistlerin seyahat motivasyonları üzerine bir araştırma. Hitit Üniversitesi Sosyal Bilimler Enstitüsü Dergisi, 11(1), 455-475.

Jang, S., ve Cai, L. (2002). Travel motivations and destination choice: A study of British outbound market. Journal of Travel \& Tourism Marketing, 13(3), 111-133.

Kavalcı, K. (2015). Tüketici karar verme tarzlar ve öğrenme stillerinin $Y$ ve Z kuşakları açısından karşılaştırılması üzerine bir araştırma. Yüksek lisans tezi, Atatürk Üniversitesi Sosyal Bilimler Enstitüsü. Erzurum. 
Kavalcı, K., ve Ünal, S. (2016). Y ve Z kuşaklarının öğrenme stilleri ve tüketici karar verme tarzları açısından karşılaştırılması. Atatürk Üniversitesi Sosyal Bilimler Enstitüsü Dergisi, 20(3), 1033-1050.

Kotler, P., ve Armstrong, G. (2004). Principles of marketing. New Jersey: Prentice Hall.

Kotler, P., Bowen, J. T., Makens, J., ve Baloglu, S. (1999). Marketing for hospitality and tourism. New Jersey: Prentice Hall.

Kurtoğlu, R., Sönmez, A. T., ve Temiz, S. (2016). Tüketicilerin yaş kuşaklarına göre wom hakkındaki değerlendirmeleri. Eurasian Business \& Economics Journal, 2(2), 416-430.

Kyles, D. (2005). Managing your multigenerational workforce. Strategic Finance, 87(6), 52-55.

Mücevher, M. H., ve Erdem, R. (2018). X kuşağı akademisyenler ile Y Kuşağı öğrencilerin birbirlerine karşı algıları. Süleyman Demirel Üniversitesi Vizyoner Dergisi, 9(22), 60-74.

Okumuş, B. E. (2016). Kuşak farkı özelliklerine göre şekillenen ofis iç mekan tasarımı kriterlerinin irdelenmesi - $Y$ ve $Z$ kuşağ üzerine araştırma ve model önerisi. Yayınlanmamış doktora tezi, Mimar Sinan Güzel Sanatlar Üniversitesi Fen Bilimleri Enstitüsü, İstanbul.

Serçek, G. Ö., ve Serçek, S. (2017). X, Y ve Z kuşaklarındaki turistlerin destinasyon imaj algilarının karşılaştırılması. Seyahat ve Otel İ̧sletmeciliği Dergisi,14(1), 6-19.

Singh, A. (2014). Challenges and issues of generation Z. Journal of Business and Management, 16(7), 59-63.

Sönmez, F. (2016). Sosyal medyanın Z kuşağı tüketicilerinin satın alma davramışları üzerindeki etkisi. Yüksek lisans tezi, Celal Bayar Üniversitesi Sosyal Bilimler Enstitüsü. Manisa

Taş, H., Demirdöğmez, M., ve Küçükoğlu, M. (2017). Geleceğimiz olan Z kuşağının çalışma hayatına muhtemel etkileri. Uluslararası Toplum Araştırmalar Dergisi, 7(13), 1031-1048.

Taşova, M. (2019). X ve Y nesillerinin motivasyon faktörleri, bireysel ve iş değerlerinin örgütsel bağglliklarnna etkisi. Doktora tezi. İstanbul Ticaret Üniversitesi Sosyal Bilimler Enstitüsü, İstanbul.

TDK. (t.y). Türkçe sözlük. 26 Aralık 2019 tarihinde https://sozluk.gov.tr/ adresinden erişilmiştir. 


\section{Kaynakça Bilgisi / Citation Information}

Çöp, S., İbiş S. ve Kızıldemir, Ö. (2020). Seyahat motivasyonlarının X, Y ve $Z$ kuşaklarına göre farklılıklarının incelenmesi üzerine bir araştırma. OPUS-Uluslararası Toplum Araştırmaları Dergisi, 16(30), 2528-2550. DOI: 10.26466/opus.693787 